\title{
Relation between dietary fat and energy and micronutrient intakes
}

\author{
S Tonstad, M Sivertsen
}

\begin{abstract}
Concern has been raised about the energy and nutrient adequacy of low fat diets for children that aim to prevent cardiovascular disease in Western populations. The diets of 174 randomly chosen schoolchildren aged 8-12 years from middle and high socioeconomic groups were analysed to determine their nutrient composition in relation to fat intake. The mean percentages of energy intake from fat and saturated fat were 31 and $13 \%$, respectively, and $44 \%$ of all children reported consuming $<30 \%$ of their energy from fat. The energy intake did not change across the spectrum of fat intake. A decreased fat intake was associated with an increased sugar intake, but also with increased nutrient densities of thiamin, niacin, folate, vitamin C, magnesium, and iron, reflecting an increased intake of fruit, vegetables, and grains. Parental educational level was the most important determinant of fat intake (inverse relation). It is concluded that a self selected low fat intake among children from average to high socioeconomic backgrounds does not compromise their intake of major nutrients or energy.

(Arch Dis Child 1997;76:416-420)
\end{abstract}

Keywords: vitamins; dietary fat; blood lipids

International comparisons have shown that geographical variations in total cholesterol concentrations appear to parallel differences in diet. ${ }^{1}$ These data, in addition to the wealth of evidence that links serum lipid concentrations with atherosclerosis and coronary artery dislines regarding the optimum diet for children in Western populations. ${ }^{2-4}$ The recommendations focus on reducing dietary total and saturated fat and cholesterol intakes, while maintaining an adequate energy intake to support growth and development.

The US recommendation to restrict total fat

Lipid Clinic, Medical Department A, National Hospital, Oslo, Norway

$S$ Tonstad

M Sivertsen

Correspondence to: Dr Serena Tonstad, Lipid Clinic, National Hospital, $\mathrm{N}-0027$ Oslo, Norway.

Accepted 28 January 1997 some countries' nutrition policies for the population over the age of 2 years. ${ }^{256}$ Others have suggested a more gradual transition from the high fat diet of infancy to a fat restricted diet at the end of linear growth, ${ }^{347}$ or a more moderate restriction of fat to $<35 \%$ of the energy intake. ${ }^{8}$ A gradual or lesser change has been recommended because of concerns that children eating a low fat diet may not meet nutrient needs ${ }^{9}$ and because of reports of ease, have led several groups to publish guide-

growth failure in children consuming 'adult' diets. ${ }^{10}$ Moreover, some workers have expressed uncertainty about the safety of diets containing $<23-24 \%$ of energy intake from fat, which would be consumed by some children if a population mean of $<30 \%$ were to be achieved. ${ }^{411}$ It has also been suggested that low fat diets may decrease high density lipoprotein (HDL) cholesterol levels ${ }^{42}$ and lower the intake of lipid soluble antioxidants. ${ }^{4}$

Replacing dietary fat with complex carbohydrates necessitates an increase in the density of several nutrients. ${ }^{13}$ Populations accustomed to high fat intakes may not, however, correctly interpret advice to restrict dietary fat and cholesterol. ${ }^{14}$ In an analysis of 10 year old children participating in the Bogalusa study, the group with the lowest fat intake had a lower energy intake, a higher sugar intake, and included more children with an insufficient intake of minerals and vitamins than the other groups. ${ }^{15}$ Likewise, a 'fat-sugar see-saw' has been shown among free living children in Edinburgh: the lower a child's intake of fat, the higher the sugar intake. ${ }^{16}$ Whether this relation is present in other populations or limited to certain segments of the population has not been clarified.

In this study we assessed the nutrient composition of the diets of a random sample of young children from middle to high socioeconomic backgrounds in relation to fat consumption.

\section{Subjects and methods}

We randomly sampled primary schools in Oslo with $\leqslant 15 \%$ of students of non-Norwegian origin according to the mean income of the population served by the schools. Four schools whose population's mean income was $25 \%$ above the mean and six schools whose income was similar to the mean of the city were included. Of students in grades 2-5 (age 8-12 years), $33 \%$ from the high income group and $48 \%$ from the middle income group participated in a study of cardiovascular risk factors (756 children). ${ }^{17}$ The study was approved by the regional medical ethics committee.

A random sample of 174 children partici- pated in a dietary study conducted during the autumn and winter seasons. The child and mother were interviewed by a dietitian (MS) about the child's diet during the past year. The interview was based on a quantitative food frequency questionnaire developed at the Institute for Nutrition Research in Oslo, ${ }^{18}$ which was read optically after completion. Computation of daily intakes of nutrients and foods was 


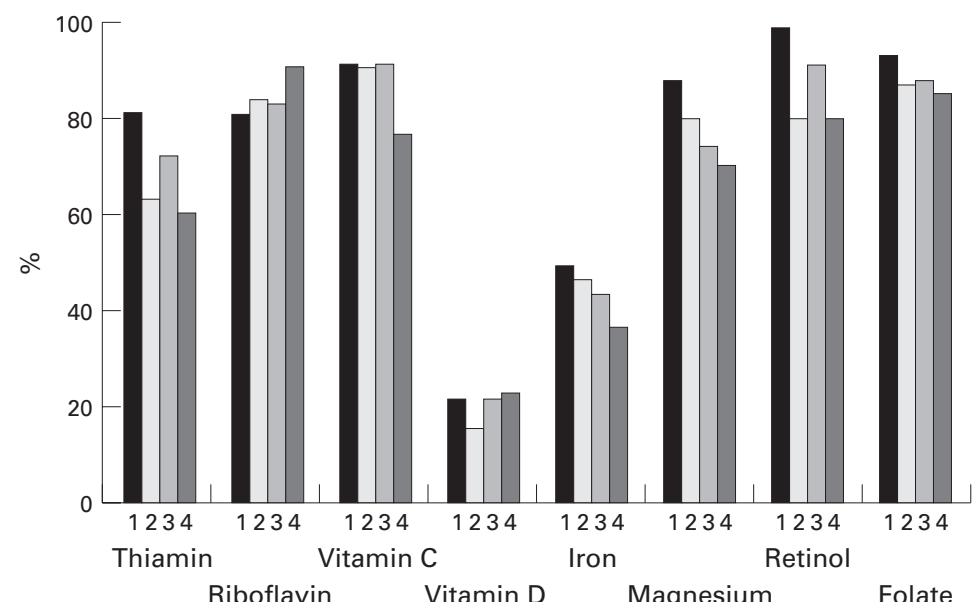

Figure 1 Intake of vitamins as a percentage of the recommended levels according to increasing quartiles of percentage energy from total fat $(n=139)$.

Table 1 Characteristics of subjects. Mean (SD) values are shown except for weight for height SD score, for which median (interquartile range) is shown

\begin{tabular}{lll}
\hline & Boys $(n=92)$ & Girls $(n=82)$ \\
\hline Age (years) & $10(1)$ & $10(1)$ \\
Height SD score & $0.26(0.93)$ & $0.33(1.07)$ \\
Weight for height SD score & $0.42(-0.21$ to 1.22$)$ & $0.45(-0.23$ to 1.34$)$ \\
Body mass index $\left(\mathrm{kg} / \mathrm{m}^{2}\right)$ & $18.0(2.6)$ & $18.2(2.7)$ \\
Total cholesterol $(\mathrm{mmol} / \mathrm{l})$ & $4.6(0.8)$ & $4.9(0.8) \dagger$ \\
HDL cholesterol (mmol/1) & $1.5(0.4)$ & $1.4(0.3)$ \\
Father's education level (scale of $1-3)$ & $2.4(0.8)$ & $2.4(0.9)$ \\
Mother's educational level (scale of $1-3)$ & $2.4(0.8)$ & $2.2(0.9)$ \\
Physical activity level (scale of $1-5)$ & $2.4(1.4)$ & $8.60(1.63) \ddagger$ \\
Energy intake (MJ) & $9.77(1.76)$ & $1.7(0.4)$ \\
Energy intake/estimated BMR & $1.8(0.4)$ & \\
\hline
\end{tabular}

$\star \mathrm{BMR}=$ basal metabolic rate.

$\dagger \mathrm{p}=0.02 ; \neq \mathrm{p}=0.0001$.
BLOOD ANALYSES

Blood samples were obtained between 9 am and noon. Serum lipid analyses were performed on the same day. Serum total and HDL cholesterol were determined enzymatically using reagents supplied by Boehringer Mannheim AG.

STATISTICAL ANALYSES

Groups were formed according to the quartile of total fat as a percentage of energy intake. We used the unpaired $t$ test and analysis of variance to compare variables in two and more than two groups, respectively. $\mathrm{p}$ Values in tables 2 and 3 show the significance of the one degree of freedom trend across the four quartile groups. Univariate regression coefficients or Spearman's rank coefficient were calculated to assess the relation between two variables that were normally distributed or skewed, respectively. Multiple regression analysis was used to identify independent determinants of fat intake. Height and weight for height SD scores were calculated using Norwegian reference data and compared with the population mean of zero with a one sample $t$ test using $n$-1 degrees of freedom. Two tailed $p$ values $<0.05$ were considered statistically significant.

\section{Results}

Of 174 subjects, $55 \%$ were from the middle income group and $45 \%$ from the high income group. The median parental educational level was high and was higher in the high than in the middle income group (2.7 $v 2.1$ for fathers, $\mathrm{p}=$ $0.0001 ; 2.6 v 2.0$ for mothers, $\mathrm{p}=0.0001$ ), confirming the middle to high socioeconomic background of the subjects. The intake of major nutrients was similar in the two income groups (data not shown). None had a previously diagnosed lipid disorder or had received dietary advice regarding fat and cholesterol intake from a health professional.

Boys and girls did not differ in regard to demographic characteristics, HDL cholesterol concentration, or physical activity level (table 1). The energy intake was higher among the boys; the girls had a higher total cholesterol level. The mean height and weight for height SD scores were higher than the population mean for both girls and boys $(p \leqslant 0.007)$. Of all the participants, $76(44 \%)$ reported consuming $<30 \%$ of energy from fat and six $(3 \%)$ reported $<10 \%$ of energy from saturated fat. Seventy seven per cent of participants took multivitamins or cod liver oil, or both, widely recommended as a source of vitamin D.

The mean total fat intake according to quartile in descending order was $35.6 \%$ (range $33.8-38.9 \%$ ), $32.4 \%$ (range $30.8-33.7 \%$ ), $29.8 \%$ (range $28.2-30.7 \%$ ), and $25.4 \%$ (range $20.2-28.1 \%$ ) of energy intake. The serum total and HDL cholesterol concentration did not differ across the spectrum of fat intake (table 2). The height SD score and energy intake/ estimated BMR did not differ according to fat intake; however, subjects in the highest fat intake quartile tended to weigh less than the rest of the subjects. Energy and protein intake did not differ according to fat intake; monoun- with recommended levels, we included only subjects whose energy intake was within the cut off points (139 children; fig 1). 
Table 2 Mean energy and macronutrient intake and serum lipids according to decreasing quartile of fat intake (median and interquartile range values shown for weight for height SD score)

\begin{tabular}{|c|c|c|c|c|c|c|}
\hline & $\underset{(n=40)}{\text { Quartile } 4}$ & $\underset{(n=47)}{\text { Quartile } 3}$ & $\underset{(n=42)}{\text { Quartile } 2}$ & $\underset{(n=45)}{\text { Quartile } 1}$ & $\begin{array}{l}\text { Pooled } \\
\text { SD }\end{array}$ & $p$ Value \\
\hline Total fat $\left(\mathrm{E} \%{ }^{\star}\right)$ & 35.6 & 32.4 & 29.8 & 25.4 & 1.4 & \\
\hline Height SD score & 0.35 & 0.33 & 0.07 & 0.42 & 0.97 & NS \\
\hline \multicolumn{7}{|l|}{ Weight for height } \\
\hline $\begin{array}{l}\text { SD score } \\
\text { Interquartile }\end{array}$ & 0.05 & 0.56 & 0.34 & 0.54 & & 0.04 \\
\hline range & -0.66 to 0.81 & -0.05 to 1.54 & -0.22 to 1.50 & -0.08 to 1.33 & & \\
\hline Energy (MJ) & 9.55 & 9.31 & 8.94 & 9.11 & 1.76 & NS \\
\hline \multicolumn{7}{|l|}{$\begin{array}{l}\text { Energy } \\
\text { intake/ } \\
\text { estimated }\end{array}$} \\
\hline BMR & 1.85 & 1.77 & 1.70 & 1.75 & 0.4 & NS \\
\hline $\begin{array}{l}\text { Saturated fat } \\
\qquad(\mathrm{E} \%)\end{array}$ & 15.3 & 13.8 & 12.8 & 11.0 & 1.4 & 0.0001 \\
\hline $\begin{array}{l}\text { Monounsaturated } \\
\text { fat }(\mathrm{E} \%)\end{array}$ & 12.2 & 11.0 & 10.1 & 8.5 & 0.8 & 0.0001 \\
\hline $\begin{array}{l}\text { Polyunsaturated } \\
\text { fat }(\mathrm{E} \%)\end{array}$ & 5.6 & 4.9 & 4.4 & 3.7 & 1.0 & 0.0001 \\
\hline Protein $(\mathrm{E} \%)$ & 14.2 & 14.3 & 14.6 & 14.4 & 1.6 & NS \\
\hline Carbohydrates & & & & & & \\
\hline$(\mathrm{E} \%)$ & 48.8 & 52.2 & 54.5 & 58.9 & 2.0 & 0.0001 \\
\hline Sugar (E\%) & 9.4 & 11.1 & 11.9 & 12.8 & 4.0 & 0.0001 \\
\hline $\begin{array}{l}\text { Cholesterol } \\
\mathrm{mg} / 4.2 \mathrm{MJ}\end{array}$ & 112 & 108 & 101 & 93 & 17 & 0.0001 \\
\hline $\begin{array}{l}\text { Total cholesterol } \\
(\mathrm{mmol} / \mathrm{l})\end{array}$ & 4.7 & 4.8 & 4.7 & 4.9 & 0.8 & NS \\
\hline $\begin{array}{l}\text { HDL cholesterol } \\
(\mathrm{mmol} / \mathrm{l})\end{array}$ & 1.5 & 1.5 & 1.4 & 1.4 & 0.4 & NS \\
\hline
\end{tabular}

$\star \mathrm{E}=$ dietary energy.

Table 3 Mean nutrient density (amount of nutrient per MF) according to decreasing quartile of fat intake

\begin{tabular}{|c|c|c|c|c|c|c|}
\hline & Quartile 4 & Quartile 3 & Quartile 2 & Quartile 1 & Pooled SD & $p$ Value \\
\hline Thiamin (mg) & 0.14 & 0.15 & 0.15 & 0.16 & 0.02 & 0.0001 \\
\hline Riboflavin (mg) & 0.21 & 0.20 & 0.21 & 0.20 & 0.03 & NS \\
\hline Niacin (mg) & 1.4 & 1.5 & 1.5 & 1.6 & 0.2 & 0.01 \\
\hline Folate $(\mu \mathrm{g})$ & 16.8 & 18.1 & 18.2 & 21.5 & 4.2 & 0.0001 \\
\hline Vitamin B12 $(\mu \mathrm{g})$ & 0.77 & 0.73 & 0.75 & 0.72 & 0.23 & NS \\
\hline Vitamin C (mg) & 8.1 & 9.7 & 9.7 & 13.9 & 5.0 & 0.0001 \\
\hline \multicolumn{7}{|l|}{ Retinol equivalents } \\
\hline$(\mu \mathrm{g})$ & 170 & 161 & 167 & 160 & 70 & NS \\
\hline Vitamin D ( $\mu \mathrm{g})$ & 0.46 & 0.44 & 0.40 & 0.35 & 0.18 & 0.002 \\
\hline Calcium (mg) & 119 & 116 & 117 & 115 & 23 & NS \\
\hline Iron (mg) & 1.1 & 1.1 & 1.2 & 1.2 & 0.2 & 0.002 \\
\hline Magnesium (mg) & 36.4 & 36.8 & 38.0 & 41.1 & 4.7 & 0.0001 \\
\hline
\end{tabular}

saturated, polyunsaturated, and saturated fat and cholesterol intake increased with increasing fat intake, whereas the intake of carbohydrates and sugar decreased (table 2). The percentage of energy intake from fat and sugar were inversely correlated (Spearman's rank correlation coefficient $r=-0.28 ; \mathrm{p}=0.0002$ ).

Densities of thiamin, niacin, folate, vitamin $\mathrm{C}$, iron, and magnesium increased with decreasing fat intake (table 3). Only the intake of vitamin $\mathrm{D}$ decreased with decreasing fat intake. The increase in vitamins and minerals with decreasing fat intake reflected the increased consumption of fruit, vegetables, and cereals. The mean intake of fruit $(80,103,95$, and 157 $\mathrm{g} / 4.2 \mathrm{MJ}$, respectively, $\mathrm{p}=0.0001)$, vegetables $(30,38,39$, and $52 \mathrm{~g} / 4.2 \mathrm{MJ}$, respectively, $\mathrm{p}=$ $0.001)$, and cereals $(23,26,28$, and $33 \mathrm{~g} / 4.2$ $\mathrm{MJ}$, respectively, $\mathrm{p}=0.002$ ) increased with decreasing quartile of fat intake. The mean intake of margarine, butter, and mayonnaise decreased with decreasing fat intake; egg, oils, fish, and the total milk intake did not differ according to quartile of fat intake, but the skimmed milk intake increased and whole milk intake decreased with decreasing fat intake (data not shown).
Of all the subjects, $\geqslant 90 \%$ met $\geqslant 100 \%$ of the recommendation for calcium and vitamin B12 and the proportion did not differ according to the quartile of fat intake. The proportion who met $100 \%$ of the recommended allowances for thiamin $(p=0.02)$, vitamin $C(p=0.0001)$, folate $(p=0.01)$, and magnesium $(p=0.05)$ increased with decreasing fat quartile; the proportion who met the allowance for vitamin $\mathrm{D}$ decreased with increasing fat quartile $(\mathrm{p}=$ 0.04 ); and there was no difference between fat quartiles in the proportion meeting the recommended allowance for retinol and riboflavin (fig1).

The educational level of the mothers and fathers was highly correlated $(r=0.5 ; \mathrm{p}=$ 0.0001 ), thus we calculated the mean parental educational level. In multivariate analysis controlling for age, sex, body mass index, and economic group, the mean parental educational level (standardised $r=-0.39 ; \mathrm{p}=0.0001$ ) was inversely correlated with the percentage of energy intake from fat.

\section{Discussion}

Our study shows that the consumption of a low fat diet by children from the middle to high socioeconomic strata of the population did not compromise the intake of key nutrients or energy. We found that the intake of several water soluble vitamins, including thiamin, niacin, folate, and vitamin $\mathrm{C}$, increased with decreasing fat intake, as well as the intake of iron and magnesium. The intake of retinol was unchanged across the spectrum of decreasing fat intake; only the vitamin D intake decreased. Our database did not include data on vitamin $\mathrm{E}$ or zinc.

Several reports have suggested that a considerable segment of the population, including children, may consume low fat diets. ${ }^{11}{ }^{1521-24}$ In our study almost half of the children reported consuming $<30 \%$ of their energy intake from fat. Previous data on the nutrient composition of self selected low fat diets are scarce. The report by Nicklas et al from Bogalusa, Louisiana found a decrease in the intake of major nutrients with decreasing fat intake; however, the low fat group also reported a lower energy intake. ${ }^{15}$ These data, in addition to data from other groups, ${ }^{25} 26$ were not checked for underreporting of energy, which often biases the results of dietary surveys. ${ }^{27}{ }^{28}$ If the total energy intake is underestimated in the population reporting a low fat intake, the intake of most nutrients will also be underestimated. Likewise, a study of predominately 3-5 year old Hispanic children reported that children reporting a low percentage of energy from fat consumed less energy, calcium, and phosphorus; however, the body mass index was increased in this group, a finding that may suggest under-reporting. ${ }^{22}$ Because the energy intake and energy intake/estimated BMR were similar in all groups in our study, the results do not appear to be biased by selective underreporting in the low fat group. We found similar results when subjects who were below or above cut off points for energy intake/estimated BMR were excluded, thus we chose to include 
all subjects to avoid difficulties in making inferences about the study population from the remainder of the random sample..$^{29}$ Excluding subjects for over-reporting may be especially dubious in the absence of data regarding total physical activity and cut off points may depend on age and growth. The sample had higher height for age and weight for height SD scores than the general Norwegian population, reflecting the fact that they were sampled from a middle to high socioeconomic group.

Our finding of an inverse relation between sugar and fat intake corroborates previous suggestions that restricting sugar intake may lead to increased fat intake and vice versa. ${ }^{16}{ }^{30-32}$ Though the sugar intake increased in the group consuming the lowest amount of fat, the increase was modest. Moreover, sugar did not displace micronutrients. The intake of fruit, vegetables, and cereals was increased in the low fat group. In accordance with these findings, a previous report showed that children from a middle to upper middle class community in Texas who reported diets with $<30 \%$ of energy from fat had similar or better nutrient intakes than the rest of the children. ${ }^{21}$ Likewise, population based studies of adults have shown increased micronutrient densities and intake of fruits and vegetables in the group eating the least fat. ${ }^{33} 34$ Only the vitamin D intake decreased with decreasing fat intake in our study. Margarine is the most important dietary source of vitamin D in Norway. Vitamin D supplementation (cod liver oil or multivitamins) is, however, recommended for the entire population, particularly during the winter months, as reflected by our finding that a large proportion of the children in the study took supplements. The intake of supplements did not differ according to the fat intake (data not shown) and would be expected to meet vitamin D needs. Notably, the low fat group consumed the same amount of milk as the rest, but substituted skimmed milk for whole milk. Thus the intake of key nutrients from milk was not compromised. Likewise, low fat meats were substituted for the usual meats and meat products (data not shown).

A low fat intake is invariably associated with a low intake of saturated fat, and it is saturated fat rather than total fat that is the most important determinant of risk of coronary heart disease and of total cholesterol concentration. The lack of an association between total fat intake and total and HDL cholesterol concentrations in this study was not surprising, given the importance of factors other than diet which affect lipid concentrations, including genetic factors, and may reflect the limited variability in intake and the small sample size. Similar findings were seen in a large sample of Swedish adolescents. $^{35}$ Moreover, though the lowest quartile of the population in regard to fat intake almost achieved the mean level of saturated fat intake $(<10 \%$ of energy) recommended by some experts, ${ }^{2}$ few reported consuming $<10 \%$ of energy from saturated fat. Though international dietary guidelines for children specify the restriction of saturated fat to $8-12 \%$ of energy, and some have suggested guidelines for polyunsaturated fat, ${ }^{348}$ Nordic policies have not yet suggested cut off levels of saturated or polyunsaturated fat intake. ${ }^{56}$ Accordingly, we found that the intake of polyunsaturated fat in our population was low and decreased with decreasing fat intake. Increased polyunsaturated and monounsaturated fat-for example, from oils, nuts, and fatty fish-may be a protective factor in regard to coronary heart disease. ${ }^{36}$ Increasing consumption of these foods may be difficult, especially among children. ${ }^{37}$

Our findings suggest that parental educational level is an important determinant of children's fat intake, after control for economic status. Thus further efforts to limit the intake of fat in the population should probably focus on children with parents from low socioeconomic backgrounds. Our finding is consistent with previous data ${ }^{38}$ and may in part be explained by the increase in food costs associated with low fat diets. ${ }^{39}$ We found a lower median weight for height in the group with the highest fat intake, possibly because the parents of the thinnest children did not perceive a need to restrict fat intake.

In conclusion, self selected low fat diets in the middle to high socioeconomic segment of the population are associated with increased parental educational level. Though the sugar intake increases with fat restriction, vitamin and mineral densities also increase due to the increased consumption of fruit, vegetables, and cereals and the substitution of skimmed milk for whole milk. Further efforts to limit the population's fat intake may need to first consider the diet of children from low socioeconomic backgrounds.

We thank Jørgen Knudtzon for calculating height for age and weight for height SD scores.

1 Labarthe DR, O'Brien B, Dunn K. International comparisons of plasma cholesterol and lipoproteins. Ann N Y Acad Sci 1991;623:108-19.

2 The Expert Panel, National Cholesterol Education Program. Report of the expert panel on blood cholesterol levels in children and adolescents. Pediatrics 1992;89:525-84.

3 Åkerblom HK, Chandra RK, Franklin FA, et al. ConcluAkerblom HK, Chandra RK, Franklin FA, et al. Conclu-
sions, guidelines and recommendations from the IUNS/ WHO workshop: nutrition in the pediatric age group and later cardiovascular disease. $\mathcal{F}$ Am Coll Nutr 1992;11 (suppl S): $1 \mathrm{~S}-2 \mathrm{~S}$.

4 ESPGAN Committee on Nutrition. Committee report: childhood diet and prevention of coronary heart disease. $\mathscr{f}$ Pediatr Gastroenterol Nutr 1994;19:261-9.

5 National Nutrition Council. Norwegian nutrient recommendations. Oslo: National Nutrition Council, 1992.

6 Nordic Committee on Foods. Nordic nutrition recommendations. 2nd Ed. Copenhagen: Nordic Committee on Foods, 1989.

7 Health and Welfare Canada. Nutrition recommendations update - dietary fat and children. Ottawa: Canadian Governupdate-dietary fat and children.

8 Department of Health. Dietary reference values for food energy Department of Health. Dietary reference values for food energy
and nutrients for the United Kingdom. Report on Health and Social Subjects No 41. London: Department of Health, Social

9 Zlotkin SH. A review of the Canadian 'Nutrition recommendations update: dietary fat and children'. F Nutr 1996; 126:1022S-7S.

10 Lifshitz F. Children on adult diets: is it harmful? Is it healthful? F Am Coll Nutr 1992;11 (suppl S):84S-90S

11 Olson RE. The dietary recommendations of the American Academy of Pediatrics. Am F Clin Nutr 1995;61:271-3.

12 Lifshitz F, Tarim O. Considerations about dietary fat restrictions for children. $\mathcal{F}$ Nutr 1996;126:1031S-41S.

13 Michaelsen KF, Jørgensen MH. Dietary fat content and energy density during infancy and childhood: the effect on energy density during infancy and childhood: the effect on

14 Harper AE. Dietary guidelines in perspective. F Nutr 1996; 126:1042S-8S. 
15 Nicklas TA, Webber LS, Koschak ML, et al. Nutrient adequacy of low fat intakes for children: the Bogalusa adequacy of low fat intakes for child
Heart Study. Pediatrics 1992;89:221-8.

16 Ruxton CHS, Kirk TR, Belton NR. Energy and nutrient intakes in a sample of 136 Edinburgh 7-8 year olds: a comparison with United Kingdom dietary reference values. $B r$ f Nutr 1996;75:151-60

17 Tonstad S, Refsum H, Sivertsen M, et al. Relation of total homocysteine and lipid levels in children to premature cardiovascular death in male relatives. Pediatr Res 1996;40: 1-6.

18 Frost Andersen L, Nes M, Lillegaard IT, et al. Evaluation of a quantitative food frequency questionnaire used in a group of Norwegian adolescents. Eur f Clin Nutr 1995;49:543-54.

19 Schofield WN. Predicting basal metabolic rate, new standards and review of previous work. Hum Nutr: Clin Nutr 1985;39C(suppl 1):5-41.

20 Torun B, Davies PSW, Livingstone MBE, et al. Energy requirements and dietary energy recommendations for requirements and dietary energy recommendations for 1996;50 (suppl 1):S37-81.

$21 \mathrm{McPherson}$ RS, Nichaman MZ, Kohl HW, et al. Intake and food sources of dietary fat among schoolchildren in the food sources of dietary fat among schoolchil

22 Shea S, Basch CE, Stein AD, et al. Is there a relationship between dietary fat and stature or growth in children three to five years of age? Pediatrics 1993;92:579-86.

23 Bergström E, Hernell O, Persson LA. Dietary changes in Swedish adolescents. Acta Paediatr 1993;82:472-80.

24 Lapinleimu H, Viikari J, Jokinen E, et al. Prospective randomised trial in 1062 infants of diet low in saturated fat and cholesterol. Lancet 1995;345:471-6.

25 Vobecky JS, Vobecky J, Marquis L. The relation between low-fat intake and vitamin status in a free-living cohort of preschoolers. Ann N Y Acad Sci 1992;669:374-8.

26 Gibson RS, Macdonald CA, Vanderkooy PDS, et al. Dietary fat patterns of some Canadian preschool children in relation to indices of growth, iron, zinc, and dietary status. relation to indices of growth, ir
Can Assoc 1993;54:33-7.

27 Hegsted DM. What are American children eating? Implications for public policy (Nutr Rev 1995;53:111-26). Nutr $\operatorname{Rev} 1$ 1996;54:67.
28 Bandini LG, Schoeller DA, Cyr HN, et al. Validity of Bandini LG, Schoeller DA, Cyr HN, et al. Validity of reported energy intake in obese
Am f Clin Nutr 1990;52:421-5.

29 Strain JJ, Robson PJ, Livingstone MBE, et al. Estimates of food and macronutrient intake in a random sample of Northern Ireland adolescents. Br F Nutr 1994;72:343-52.

30 Bolton-Smith C, Woodward M. Dietary composition and fat to sugar ratios in relation to obesity. Int $\mathcal{F}$ Obes $1994 ; 18$ : 820-8.

31 Baghurst KI, Baghurst PA, Record SJ. Demographic and dietary profiles of high and low fat consumers in Australia. dietary profiles of high and low fat consumers

32 Boulton TJC, Magarey AM. Effects of differences in dietary fat on growth, energy and nutrient intake from infancy to eight years of age. Acta Paediatr 1995;84:146-50

33 Pryer J, Brunner E, Elliott P, et al. Who complied with COMA 1984 dietary fat recommendations among a nationally representative sample of British adults in 1986-7 and what did they eat? Eur F Clin Nutr 1995;49:718-28.

34 Ursin G, Ziegler RG, Subar AF, et al. Dietary patterns associated with a low-fat diet in the National Health Examination Follow-up Study: identification of potential confounders for epidemiologic analyses. Am $\mathcal{f}$ Epidemiol 1993;137:916-27.

35 Bergström E. Cardiovascular risk indicators in adolescents. The Umeå Youth Study. Umeå: Umeå University Medical Dissertations, 1995

36 Mann J. Position statement: nutrition options when reducing saturated fat intake. $\mathcal{f}$ Am Coll Nutr 1992; 11(suppl S):82S-3S

37 Tonstad S, Sivertsen M. Food dislikes and dietary intake in children with familial hypercholesterolemia and controls. Scand F Nutr 1996;40:146-50

38 Laitinen S, Räsänen L, Viikari J, et al. Diet of Finnish children in relation to the family's socio-economic status. Scand F Soc Med 1995;23:88-94.

39 Stender S, Skovby F, Haraldsdottir J, et al. Cholesterollowering diets may increase the food costs for Danish children. A cross-sectional study of food costs for Danish children with and without familial hypercholesterolaemia. Eur f Clin Nutr 1993;47:776-86. 